\title{
Public input sought on transgenic farming
}

\section{Claire Tilstone, London}

A fresh method for assessing public opinion on scientific matters is being tested in Britain this month. But observers of the process, which aims to assess opinion about genetically modified crops through a series of public debates, say it may need more money and better planning if it is to succeed.

The debates are part of the government's attempts to assess opinion ahead of this autumn's decision on whether to allow commercial planting of herbicide-resistant crops. Some conventional methods are being employed - standard social-research protocols, for example, are being used in focus groups. But the panel of academics and industry representatives charged with overseeing the process has also opted for a more novel approach - six public debates, held this month in towns around Britain, which are designed to spark off many smaller debates among community organizations.

When Nature attended the second debate, held in Swansea in Wales on 5 June, things got off to a shaky start. Those who arrived for the advertised 18:00 start found they had missed the introductory video, which had begun half an hour before. And attendees were split into groups and presented with a series of fact sheets, rather than being allowed to question a panel of experts. "There isn't anyone here who can tell us the facts," said one participant.

The ensuing hour-long debate proved to be a bumpy ride. A local organic farmer, who was

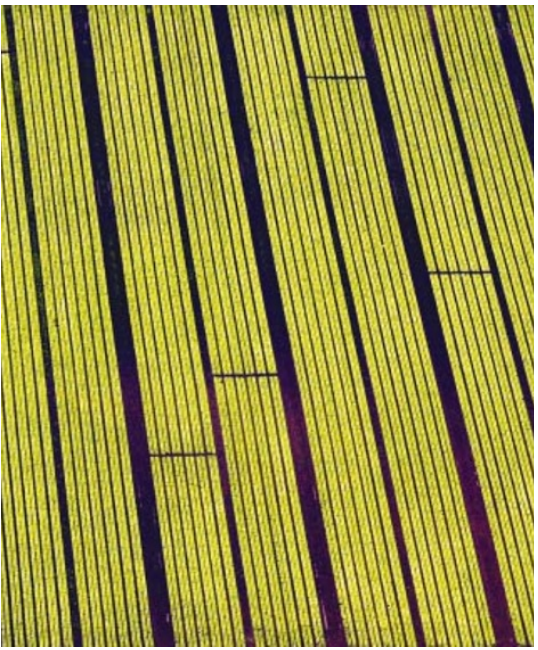

Strands of opinion: transgenic crops are a source of continuing public debate in Britain.

strongly against transgenic crops, had reams of documents backing up points she made. Her assertive approach seemed to make it difficult for those with less experience of the topic to get involved. At the end of the debate, none of the eight members of Nature's table had changed their feelings about transgenic crops.

The events are meant to encourage people to set up their own smaller debates among friends, colleagues or community groups, and supporting materials such as a CD-ROM and video are available. The results of these smaller debates will be collected through a questionnaire that asks people to what extent they agree with certain statements about genetically modified crops and invites them to give their views. They can also complete this questionnaire on the 'GM Nation?' website. The government hopes by this to develop a more sophisticated picture of public opinion than surveys and focus groups can provide.

But those involved admit that the debates may not be reaching people who are undecided about transgenic crops but wish to know more. The Swansea meeting, like the opening meeting in Birmingham on 3 June, attracted just a few hundred people.

The low attendance, and lack of interest from people new to the topic, may be due to poor advertising. The government originally allocated the debates just $£ 250,000$ (US\$410,000) in funding, upped to $£ 500,000$ after complaints from the panel of organizers. Similar debates held in New Zealand and the Netherlands over the past three years received around $£ 2$ million in government funding.

"We have been severely constrained by money," says Gary Kass, an adviser at the Parliamentary Office of Science and Technology, and a member of panel. But ministers insist that they will consider the results of the debates alongside the findings of an ongoing review of scientific studies of transgenic crops, together with the results of a farm-scale trial of such crops, which began in 2000 .

www.gmpublicdebate.org

\section{All change as Argentina's science leader keeps his job}

\section{Carol Marzuola, Caracas}

Argentina hasn't enjoyed much continuity of late. So hard-pressed scientists are relieved that newly elected president Néstor Kirchner plans to leave the country's top scientific administrator in place.

Kirchner's administration will retain Eduardo Charreau as the president of the National Council for Science and Technology (CONICET), the country's main science agency. "It's the first time in history that CONICET authorities won't change with a new president," says Charreau, a molecular endocrinologist and former director of the Institute of Biology and Experimental Medicine in Buenos Aires.

Tulio Del Bono, a political ally of the president, has been appointed secretary of science and technology, overseeing CONICET. Del Bono, an engineer and former rector of the National University of San Juan, helped Kirchner on science and technology aspects of his campaign - most notably, a bold pledge to increase total spending on research and development from $0.4 \%$ to $1.0 \%$ of economic output by 2006 .

This year, the Argentinian government will spend about $\$ 400$ million on supporting an estimated 21,000 researchers, including about 3,500 scientists at 116 CONICET laboratories.

CONICET's budget for 2003 is up 30\% in Argentinian pesos to a total of $\$ 80$ million - still little more than half the $\$ 150$ million it received two years ago, before the drastic devaluation of the peso. But Charreau admits that much more is needed to rescue research from the impact of the devaluation and associated high inflation. "Frankly," he says, "the system is beat up and needs an urgent budgetary reactivation."

Charreau says his biggest challenge has been simply to "keep the doors of its institutions open" - for which Argentinian scientists thank him and departing science and technology secretary Julio Luna.

Del Bono says his main aim will be to attract more private money into research, to address social and economic problems. "Our emphasis and specific instructions are to fortify science and technology and to ensure that production coming out of this system can be rapidly applied," he says.

Top research priorities will be health, agriculture and livestock, and sustainable development of natural resources, he says. He wants to reduce dependency on imported medicine, for example, by supporting scientists who develop generic drugs.

But Del Bono insists that the emphasis on applied research won't be allowed to hurt basic research at CONICET, which he calls "the spinal cord of our system".

Scientists are cautiously optimistic about the new team. "We are all hopeful," says Conrado Varroto, director of Argentina's space agency in Buenos Aires. "The new authorities, in principle, recognize the importance that science and technology has for the development of the country."

www.conicet.gov.ar

www.secyt.gov.ar 